\title{
The Effect of Health Education on Dietary Knowledge and Practices of Pregnant Women in Jordan: A Quasi-Experimental Study
}

\author{
Nesrin N Abu-Baker (D) \\ Hanan A Abusbaitan' \\ Safa A Al-Ashram ${ }^{2}$ \\ Ali Alshraifeen (iD) ${ }^{3}$ \\ 'Faculty of Nursing, Community and \\ Mental Health Nursing Department, Jordan \\ University of Science \& Technology, Irbid, \\ Jordan; ${ }^{2}$ Consultantation, Secretary \\ General-Civil Service Bureau, Amman, \\ Jordan; ${ }^{3}$ Faculty of Nursing, Department of \\ Adult Health Nursing, The Hashemite \\ University, Zarqa, Jordan
}

Background: Evidence reported inadequate dietary practices among pregnant women and recommended educating pregnant women about their diet to improve pregnancy outcomes. However, studies examining the effect of health education about dietary practices during pregnancy are lacking in Jordan.

Objective: To examine the effect of health education on the levels of dietary knowledge and practices among pregnant women in Jordan.

Methods: A quasi-experimental design (pretest-posttest control group) was used. A consecutive sample of 195 pregnant women was recruited from four public health centers in Jordan; two health centers formed the intervention group $(n=95)$ and two formed the control group ( $\mathrm{n}=100)$. A structured questionnaire was used to assess dietary knowledge and practices before and after the intervention. The intervention group received health education for one month, while the control group received routine antenatal care. Data were collected from September to November 2019.

Results: After health education, the intervention group recorded significantly higher dietary knowledge score $($ mean $=19.30, \mathrm{SD}=0.88$ ) compared to the control group score (mean= 14.36, $\mathrm{SD}=2.11), p<0.001$. In addition, the intervention group reported significantly higher dietary practices score (mean $=8.70, \mathrm{SD}=1.16$ ) compared to the control group score (mean= 7.02, $\mathrm{SD}=1.66), p<0.001$. In particular, the intervention group recorded a significant increase in dietary knowledge score from the pretest (mean $=14.60, \mathrm{SD}=2.53$ ) to posttest $($ mean $=19.30, \mathrm{SD}=0.88)$, as well as practices score from the pretest $($ mean $=6.69, \mathrm{SD}=1.97)$ to posttest (mean $=8.70, \mathrm{SD}=1.16), p<0.001$.

Conclusion: Providing health education concerning dietary knowledge and practices in the care of pregnant women may improve their knowledge and practices. Nurses and midwives in primary care centers have an essential role in assessing this knowledge and providing health education for pregnant women.

Keywords: dietary knowledge, dietary practices, health education, pregnant women, Jordan

\section{Introduction}

Pregnancy is a sensitive and critical period in women's lives and introduces various physical, physiological, hormonal, and anatomical changes. These changes require lifestyle modifications by pregnant women. ${ }^{1,2}$ Yet, pregnant women should consume a healthy diet that is necessary for the growth and development of their fetus. ${ }^{1}$ According to the World Health Organization [WHO], a healthy diet consists of sufficient energy, protein, vitamins, and minerals obtained from diverse food. ${ }^{3}$
Correspondence: Nesrin N Abu-Baker Faculty of Nursing, Community and Mental Health Nursing Department Jordan University of Science \&

Technology, P.O Box 3030, Irbid, 221 I0 Jordan

Tel +96227201000 Ext. 23620

Fax +96227201065

Email nesrin@just.edu.jo 
Deficient nutrition during pregnancy may produce adverse complications on the fetus such as neural tube defects, intrauterine growth retardation, and low birth weight. ${ }^{4,5}$ Deficient nutrition may also create complications among pregnant women such as anemia, miscarriage, pregnancyinduced hypertension, gestational diabetes, and early or cesarean delivery. ${ }^{5,6}$

Pregnant women's knowledge about nutrition is a vital element in ensuring positive results of pregnancy, whether for the woman or fetus. ${ }^{7}$ Evidence suggests that women in many countries report inadequate dietary knowledge and practices during pregnancy. This was the case among 616 pregnant women in Ethiopia where 38.6\% of them had poor dietary knowledge and $60.7 \%$ reported poor dietary practices. $^{8}$ In agreement, it was also reported among Syrian refugee women in Lebanon that they had insufficient dietary knowledge and poor dietary practices during pregnancy $\left(56 \%\right.$ and $47 \%$, respectively). ${ }^{9}$ In contrast, a study in Nigeria reported excellent knowledge among $62 \%$ of 244 pregnant women, yet this knowledge did not improve dietary practices in $50 \%$ of the participants. ${ }^{10}$

The WHO (2016) recommends that health care professionals should provide nutrition education at each antepartum visit. Previous studies have shown the positive effect of health education on the levels of dietary knowledge and practices of pregnant women. ${ }^{11}$ For example, examining the impact of nutrition education on dietary knowledge and practices among 406 pregnant women in Ethiopia, it was found that knowledge of healthy nutrition increased from $53.9 \%$ to $97 \%$ and dietary practice improved from $46.8 \%$ to $83.7 \% .^{5}$ Findings from another quasiexperimental study in Iran among 100 pregnant women confirmed that the awareness levels of healthy nutrition have increased from $3 \%$ before the intervention to $31 \%$ after. ${ }^{12}$ Consistently, in a randomized clinical trial (RCT) among 360 pregnant women in Australia, it was shown that antenatal dietary behaviors and physical activity had improved in the intervention group compared to the control group. ${ }^{13}$

In Jordan, previous studies have reported inadequate dietary practices among pregnant women and recommended educating them about their diet to improve pregnancy outcomes. ${ }^{14,15}$ However, studies examining the effect of health education about dietary practices during pregnancy are lacking. For example, a study among 103 Jordanian pregnant women reported that more than $50 \%$ of the participants skipped breakfast and that their daily intake of protein, vitamins, folic acid, and calcium was less than the Dietary Reference Intakes (DRIs). ${ }^{14}$ The routine care provided in antenatal clinics in Jordan includes services such as obtaining the obstetrical history, detecting any current complications, examining fetal growth, monitoring blood pressure, testing of urine and blood, and providing health education mainly about family planning and breastfeeding by nurses and midwives. ${ }^{16}$ Thus, providing health education about nutrition during pregnancy is missing and, therefore, testing its effectiveness merits investigation.

This study was carried out to examine the effect of health education on the levels of dietary knowledge and practices among pregnant women in Jordan. We hypothesized that, providing health education effectively improves dietary knowledge and practices among pregnant women in Jordan. It is hoped that the findings from our study may provide directions on how health care providers and policymakers can improve and promote pregnant women's dietary knowledge and healthy practices, which may improve the quality of antenatal health services and increase their satisfaction with the care provided.

\section{Materials and Methods Design and Study Sites}

A quasi-experimental design (pretest-posttest control group) was employed in four randomly selected public health centers located in Amman; the capital and central part of Jordan. These four centers were randomly selected using a randomly numbered table Two of these health centers were randomly assigned as an intervention group and two as a control group. The researcher randomly selected two pieces of paper out of four to assign the intervention groups. Data about demographic variables, obstetric history, and dietary knowledge and practices were collected from both groups before and after the intervention. Health care services in Amman are covered by 122 health centers. On average, about 50-60 pregnant women visit the antenatal clinic in the health center daily and receive routine antenatal care such as obtaining the obstetrical history, detecting any current complications, examining fetal growth using ultrasound, monitoring blood pressure, and testing of urine and blood.

\section{Study Population and Sampling}

The population of this study included pregnant women receiving antenatal care in public health centers. The inclusion criteria were Jordanian pregnant women, aged 
18-40 years, and in the first or second trimesters to receive health education and continue the follow-up. The exclusion criteria included pregnant women with any medical problems or chronic diseases during pregnancy such as gestational diabetes, preeclampsia, hypertension, or coronary heart disease to exclude the effect of other factors on the study outcomes.

Based on $\mathrm{G}^{*}$ power (2014) for the calculation of the sample size ( $F$-test and four groups), and using the power level of 0.05 with a medium effect size (alpha $=0.05$ and $1-\beta=0.80)$, the minimum required total sample size was 180 participants. The researcher used a consecutive sampling approach; any pregnant woman who was available at the time of data collection, met the inclusion criteria, and agreed to participate was selected. To compensate for attrition, the researcher approached 279 pregnant women who were available in the antenatal clinic to establish their willingness to participate. Of them, 233 women met the inclusion criteria, of which 216 women agreed to participate giving an initial response rate of $92.7 \%$. Gupta et al (2016) stated that if $\mathrm{n}$ is the sample size required (180 in this study) as per formula and if $\mathrm{d}$ is the dropout rate (usually $10 \%$ to $20 \%$ ), then the adjusted sample size N1 is obtained as $\mathrm{N} 1=\mathrm{n} /(1-\mathrm{d}) .{ }^{17}$ This means that a minimum of 212 participants were needed to be enrolled in our study (216 were enrolled). Two health centers formed the intervention group and two formed the control group.

\section{Data Collection Tools}

A structured questionnaire was used based on the instruments used in previous studies. ${ }^{7-9}$ Minor modifications were made to accommodate the Jordanian culture and achieve the study purpose. To ensure the validity of the modified questionnaire, content and face validity were examined by a panel of nursing faculty experts. The questionnaire was translated into Arabic and back translated into English to ensure its reliability (ie, the consistency between the two English versions). The Cronbach's alpha (ie, internal consistency) for the questionnaire was 0.83 suggesting that it was reliable.

The questionnaire included two sections; demographic variables and obstetric history/dietary knowledge and practices during pregnancy. The first part of the demographic variables and obstetric history consisted of variables such as age, educational level, occupation, family income, height and weight before and during pregnancy, medical problems during pregnancy, gestational weeks, number of pregnancies, parity, number of children, and number of abortions. Obstetric history was obtained from pregnant women's medical records upon their permission.

The second part of the dietary knowledge and practices questionnaire comprised 28 items (18 for dietary knowledge and 10 for dietary practices). The dietary knowledge items were about the importance of food for mother and fetus, components of a balanced diet, causes of undernutrition, appropriate weight gain during pregnancy, obesity and pregnancy problems, normal body mass index, consequences of inadequate diet, sources of essential nutrients during pregnancy, and food and drinks that enhance or inhibit iron absorption. Additionally, the items of dietary practices were about adding or skipping a meal, taking iron supplements, eating protein, carbohydrates, fruits and vegetables, following weight, reducing caffeine intake, and smoking during pregnancy.

\section{Ethical Considerations}

The data collection began after obtaining approval from the Institutional Review Board (IRB) of Jordan University of Science and Technology (reference \# 80/124/2019) and the Ministry of Health (MOH). In addition, this study was conducted in accordance with the Declaration of Helsinki. The second author, who is a registered female nurse, met the directors of the health centers and gained permission to collect data. The researcher explained the study's objectives, its benefits, and its duration to the participants. The participants were asked for permission to access their personal and medical information from their medical records. Informed consent was obtained from each participant. Participants were informed that participation was voluntary, they could withdraw from the study at any time, and that their data would remain confidential. All participants' contacts were obtained for further arrangements and appointments.

\section{Data Collection Procedure}

The participants were assigned into experimental and control groups according to the randomly assigned health centers. Twelve groups (6 interventions and 6 controls) were created using WhatsApp application for further arrangement and follow-up purposes. The researcher contacted each group and assigned a suitable date and time for the pretest, which was the same day as the educational session for the intervention groups. For the intervention groups, pretest structured questionnaires were completed face-to-face before the conduction of onsite educational sessions on six occasions and the posttest only was 
collected using phone calls after six weeks. It took 15-20 minutes to complete the questionnaires. For the control groups, pretests were collected on six onsite occasions and the same groups completed the posttest after six weeks using phone calls. Data were collected from September to November 2019. Any woman who was absent from her assigned group at the time of data collection was asked to join the next group meeting. All meetings to fill the pretest questionnaire and provide health education were conducted in a meeting room in the selected health center by the same researcher. The researcher was present during this time to clarify any inquiry.

\section{Health Education}

The intervention groups were informed that the period of health education was one month. The intervention consisted of a 2-hour health education session followed by the distribution of written materials. All materials were presented in the Arabic language and were translated and back translated by professional translators and checked by a panel of experts for their content validity. A qualified nurse with four years of experience in nursing provided health education. The qualified nurse visited both health centers of the intervention groups six times (ie, three times for each health center) to provide six onsite health education sessions. At each visit, the nurse researcher gathered the assigned subgroup of 15-18 pregnant women in the meeting room where pretest structured questionnaires were completed. Then, one educational lecture was delivered for that group. At the end of the lecture, brochures were distributed to support the explained lecture. The researcher used WhatsApp application after that to communicate added information about dietary knowledge and practices to women at home using tips and videos. The researcher answered all questions by participants using phone calls or through text messages. After six weeks, the posttest was collected from all subgroups using phone calls.

The nurse implemented an interactive lecture using PowerPoint presentations and discussions with participants to increase the level of dietary knowledge and practices. Strengthening individuals' knowledge of the topic such as understanding the benefits of a healthy diet and using interactive learning are among the successful nutrition interventions. ${ }^{18}$ Examples of the topics covered are the physiological changes that occur in pregnant woman, the importance of diet and supplements for pregnant women and the fetus, the six categories of nutrition, the daily needs of diet during pregnancy, the normal weight gained during pregnancy, and the body mass index categories and its calculation. The teaching materials were adopted from "Healthy Eating during Pregnancy and Breastfeeding", 19 "Nutrition of Women in the Preconception Period, during Pregnancy and the Breastfeeding Period", ${ }^{20}$ and "Diet during Pregnancy: Healthy Eating While Pregnant". ${ }^{21}$ The control group received usual antenatal care in the two other health centers. No questions or discussions were opened about dietary knowledge and practices during pregnancy with the control group. Six weeks after the intervention, a posttest was obtained from all participants in both groups.

\section{Data Analysis Procedures}

The items of dietary knowledge included "yes/no" and multiple-choice answers. For each "yes/no" question, an incorrect response was coded as 0 , and a correct response was coded as 1. Further, the multiple-choice questions were coded as 0 for do not know, 1 for the incomplete correct answer, and 2 for the complete correct answer. The total score of knowledge ranged from 0 to 20 for the 18 items (only two questions received the highest score of two). Additionally, the items of dietary practices included "yes/no" answers and the total score of practices score ranged from 0 to 10 for the ten items; an incorrect response was coded as 0 and a correct response was coded as 1 .

The IBM SPSS Statistics for Windows, version 25, was used for data analysis. The descriptive statistic was used to describe all variables in the study such as means, standard deviations, frequencies, and percentages. The Independent Samples $t$-Test was used to compare the main study variables (knowledge and practice) between the control and intervention groups. A paired sample $t$-test was used for a pretest and posttest comparison of the study variables within each group. The statistical significance was set at 0.05 .

\section{Results}

\section{Socio-Demographic Characteristics}

The initial intervention group included 108 participants (54 participants from each center) and the initial control group included 108 participants (54 participants from each center). Of the 216 pregnant women who met the inclusion criteria, 195 participants completed the study giving a final response rate of $90.3 \%$ (Figure 1). The mean age of 


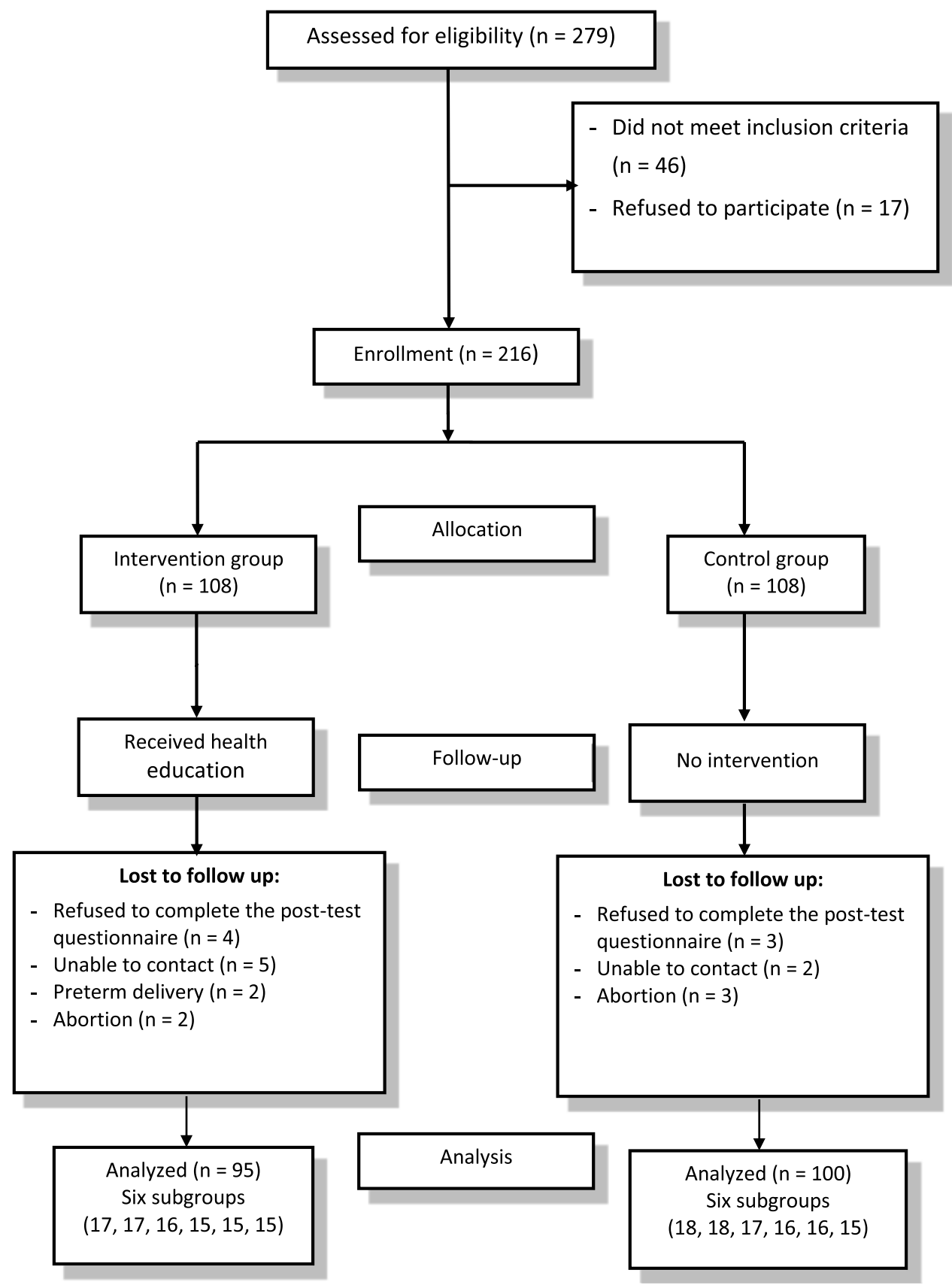

Figure I Total sample size.

participants was 28.38 years $(S D=6.18)$ and the mean family monthly income was $470.95 \mathrm{JD}(\mathrm{SD}=256.63) ; 1$ Jordanian Dinar $=0.71$ US dollars. The mean weight before pregnancy was $61.85(S D=12.79)$ and the mean weight during pregnancy was $67.18(\mathrm{SD}=12.13)($ Table 1$)$. The independent sample $t$-test was calculated to identify whether there was a significant difference between the intervention and control groups in terms of continuous demographic and obstetric variables. The results showed no significant difference between the two groups $(P>0.05)$ before health education, which decreased the probability of bias (Table 2). In addition, $66.7 \%$ of the participants had a high school or less and $75.9 \%$ were unemployed. A chisquare test was also calculated to identify the difference between both groups in terms of nominal demographic variables. The results indicated that there was no significant difference between the intervention and control groups in terms of education level $\left.\chi^{2}(1, \mathrm{n}=195)=0.029, p=0.685\right)$ and employment status $\left.\chi^{2}(1, \mathrm{n}=195)=0.146, p=0.127\right)$ before health education as well. 
Table I Socio-Demographic and Obstetric Characteristics of the Study Sample $(n=195)$

\begin{tabular}{|l|l|}
\hline Variables & Mean (SD) \\
\hline Age & $28.38(6.18)$ \\
Height & $159.16($ I2.98) \\
Monthly family income & $470.95(256.63)$ \\
Weight before pregancy & $6 I .85(I 2.79)$ \\
Weight during pregnancy & $67.18(12.13)$ \\
Number of pregnancies & $4.13(2.58)$ \\
Parity & $2.5 \mathrm{I}(2.14)$ \\
Number of abortions & $0.68(0.99)$ \\
Number of children & $2.55(2.12)$ \\
Hemoglobin during first trimester & $\mathrm{II} .62(\mathrm{I} .4 \mathrm{I})$ \\
\hline
\end{tabular}

\section{Dietary Knowledge Among the Two Groups Before and After the Intervention}

Before health education, most participants in the control and intervention groups reported adequate knowledge about certain items. For example, $100 \%$ vs $98.9 \%$ of the participants in the control and intervention groups correctly answered that "Food is important for growth and development of the fetus" and 98\% vs.96.8\% correctly answered that "Food is important for providing heat and energy and for the normal functioning of women's bodies". In addition, $92 \%$ vs $87.4 \%$ correctly answered that "Food is important for fighting infection or disease" and $95 \%$ vs $89.5 \%$ correctly answered that "The balanced diet is the diet that contains all the six nutrients".

On the other hand, $70.5 \%$ of the participants in the intervention group provided a correct answer about the item "When a diet for pregnant women lacks iron, health risks can occur including anemia" before health education. This percentage has increased to $98.9 \%$ after health education. In addition, $77.9 \%$ of the participants in the intervention group recognized that "Vitamin $\mathrm{C}$ rich food enhances iron absorption when taken with meals" before health education. This percentage has also increased to $96.8 \%$ after health education. Only $13.7 \%$ of the participants in the intervention group correctly answered that "Body mass index (BMI) of less than $18.5 \mathrm{~kg} / \mathrm{m}^{2}$ is a suitable weight during pregnancy" before health education, which has increased to $20 \%$ after health education. Also, $60 \%$ of the participants in the intervention group correctly answered that "If a woman had a normal weight before pregnancy, she should gain weight between $11.5 \mathrm{~kg}$ and $16.0 \mathrm{~kg}$ during pregnancy" before health education. This percentage has increased to $90.5 \%$ after health education. The proportions of participants in the control group who provided correct answers about the previous items were similar to the proportions of the intervention group before health education. However, the proportions of correct answers did not change among the control group after health education, as this group did not receive any health education (Table 3).

Before health education, the result revealed no significant difference between the total dietary knowledge score of the intervention group (mean $=14.60, \mathrm{SD}=2.53$ ) compared to the control group score $($ mean $=14.38, \mathrm{SD}=2.08),(t(193)=0.66$, $p=0.50)$. After health education, the intervention group recorded significantly higher total dietary knowledge score (mean=19.30, $\mathrm{SD}=0.88$ ) compared to the control group score $($ mean $=14.36, \mathrm{SD}=2.11),(t(193)=21.12, p<0.001)$. Furthermore, the result revealed a significant increase in the total dietary knowledge score in the intervention group from the pretest $($ mean $=14.60, \mathrm{SD}=2.53$ ) to the posttest $(\mathrm{mean}=19.30, \mathrm{SD}=0.88),(t(94)=-19.21, p<0.001)$. However, no significant difference was found in the total dietary knowledge score in the control group from the pretest

Table 2 Comparison of Socio-Demographic and Obstetric Variables Between the Study Groups Before the Intervention (N= 195)

\begin{tabular}{|l|l|l|c|c|c|c|}
\hline Variables & Intervention Group Mean (SD) & Control Group Mean (SD) & t & df & P & Mean Differences \\
\hline Age & $29.07(5.94)$ & $27.73(6.35)$ & 1.52 & 193 & 0.121 & 1.34 \\
Height & $159.60(6.17)$ & $158.74(17.13)$ & 0.46 & 193 & 0.642 & 0.86 \\
Monthly family income & $490.32(277.31)$ & $451.60(235.16)$ & 1.05 & 193 & 0.291 & 38.71 \\
Weight before pregancy & $61.83(10.72)$ & $61.87(14.55)$ & -0.02 & 193 & 0.983 & -0.03 \\
Weight during pregnancy & $66.00(11.49)$ & $68.30(12.67)$ & -1.32 & 193 & 0.184 & -2.29 \\
Number of pregnancies & $4.40(2.55)$ & $3.88(2.59)$ & 1.41 & 193 & 0.162 & 0.52 \\
Parity & $2.66(2.04)$ & $2.37(2.23)$ & 0.95 & 193 & 0.344 & 0.29 \\
Number of abortions & $0.76(0.93)$ & $0.60(1.04)$ & 1.11 & 193 & 0.263 & 0.15 \\
Number of children & $2.61(1.99)$ & $2.50(2.25)$ & 0.36 & 193 & 0.712 & 0.11 \\
Hb during first trimester* & $11.48(1.29)$ & $11.77(1.51)$ & -1.43 & 193 & 0.153 & -0.29 \\
\hline
\end{tabular}

Note: *Hemoglobin during first trimester. 
Table 3 Dietary Knowledge of Pregnant Women $(n=195)$

\begin{tabular}{|c|c|c|c|c|c|c|}
\hline \multirow[t]{2}{*}{ \# } & \multirow[t]{2}{*}{ Items } & \multirow[t]{2}{*}{ Correct Response } & \multicolumn{2}{|c|}{$\begin{array}{l}\text { Control Group } \\
(n=100)\end{array}$} & \multicolumn{2}{|c|}{$\begin{array}{l}\text { Intervention Group } \\
(n=95)\end{array}$} \\
\hline & & & $\begin{array}{l}\text { Pre } \\
\text { N (\%) }\end{array}$ & $\begin{array}{l}\text { Post } \\
\text { N (\%) }\end{array}$ & $\begin{array}{l}\text { Pre } \\
\text { N (\%) }\end{array}$ & $\begin{array}{l}\text { Post } \\
\text { N (\%) }\end{array}$ \\
\hline 1 & $\begin{array}{l}\text { Food is important for the growth and development of } \\
\text { the fetus. }\end{array}$ & Yes & $100(100 \%)$ & $100(100 \%)$ & 94 (98.9\%) & $95(100 \%)$ \\
\hline 2 & $\begin{array}{l}\text { Food is important for providing heat, energy, and for } \\
\text { the normal functioning of a women's body. }\end{array}$ & Yes & $98(98 \%)$ & 98 (98\%) & $92(96.8 \%)$ & $95(100 \%)$ \\
\hline 3 & Food is important for fighting infection or disease. & Yes & 92 (92\%) & 93 (93\%) & $83(87.4 \%)$ & $93(97.9 \%)$ \\
\hline 4 & $\begin{array}{l}\text { The balanced diet is the diet that contains all the six } \\
\text { nutrients such as carbohydrates, lipids, proteins, } \\
\text { vitamins, minerals, and water. }\end{array}$ & Yes & 95 (95\%) & 95 (95\%) & $85(89.5 \%)$ & $95(100 \%)$ \\
\hline 5 & $\begin{array}{l}\text { Women's diet during pregnancy is different from } \\
\text { others. }\end{array}$ & Yes & $87(87 \%)$ & $87(87 \%)$ & $78(82.1 \%)$ & $93(97.9 \%)$ \\
\hline \multirow[t]{3}{*}{6} & \multirow[t]{3}{*}{ Causes of undernutrition. } & $\begin{array}{l}\text { Not consuming enough } \\
\text { food }\end{array}$ & $26(26 \%)$ & $26(26 \%)$ & $29(30.5 \%)$ & 87 (91.6\%) \\
\hline & & $\begin{array}{l}\text { Food does not contain } \\
\text { enough nutrients }\end{array}$ & $59(59 \%)$ & $59(59 \%)$ & $44(46.3 \%)$ & $82(86.3 \%)$ \\
\hline & & Others (eg sickness) & $26(26 \%)$ & 27 (27\%) & $29(30.5 \%)$ & $86(90.5 \%)$ \\
\hline \multirow[t]{4}{*}{7} & \multirow{4}{*}{$\begin{array}{l}\text { When a diet for pregnant women lacks iron, health } \\
\text { risks can occur, including. }\end{array}$} & Anemia & 59 (59\%) & $58(58 \%)$ & 67 (70.5\%) & 94 (98.9\%) \\
\hline & & General weakness & $38(38 \%)$ & $38(38 \%)$ & 29 (30.5\%) & 95 (100\%) \\
\hline & & Difficult delivery & $20(20 \%)$ & $2 I(2 \mid \%)$ & $9(9.5 \%)$ & $78(82.1 \%)$ \\
\hline & & Low birth weight & $24(24 \%)$ & 24 (24\%) & $8(8.4 \%)$ & 75 (78.9\%) \\
\hline 8 & $\begin{array}{l}\text { Examples of food that enhance iron absorption when } \\
\text { taken with meals. }\end{array}$ & $\begin{array}{l}\text { Vitamin C-rich food, } \\
\text { such as fresh citrus fruits } \\
\text { (orange, lemons, etc.) }\end{array}$ & $63(63 \%)$ & $63(63 \%)$ & 74 (77.9\%) & 92 (96.8\%) \\
\hline 9 & $\begin{array}{l}\text { Examples of drinks that inhibit iron absorption when } \\
\text { taken with meals. }\end{array}$ & $\begin{array}{l}\text { Coffee, tea, Nescafé, } \\
\text { carbonated beverages. }\end{array}$ & 86 (86\%) & 86 (86\%) & 90 (94.7\%) & 95 (100\%) \\
\hline 10 & $\begin{array}{l}\text { Obese women are at an increased risk of several } \\
\text { pregnancy problems. }\end{array}$ & Yes & $88(88 \%)$ & $88(88 \%)$ & 85 (89.5\%) & 93 (97.9\%) \\
\hline 11 & $\begin{array}{l}\text { If a woman was a normal weight before pregnancy, she } \\
\text { should gain weight between II.5-16.0 kg during } \\
\text { pregnancy. }\end{array}$ & Yes & 55 (55\%) & 55 (55\%) & $57(60 \%)$ & $86(90.5 \%)$ \\
\hline 12 & $\begin{array}{l}\text { A body mass index of less than } 18.5 \mathrm{~kg} / \mathrm{m}^{2} \text { is a suitable } \\
\text { weight during pregnancy. }\end{array}$ & No & 15 (15\%) & 15 (15\%) & $13(13.7 \%)$ & $19(20 \%)$ \\
\hline 13 & Inadequate diet can cause miscarriage and stillbirth. & Yes & $52(52 \%)$ & $52(52 \%)$ & $65(68.4)$ & 89 (93.7\%) \\
\hline 14 & $\begin{array}{l}\text { Grains, vegetables (such as roots \&tubers), fruits, } \\
\text { honey, sugar, milk are some examples of carbohydrate- } \\
\text { source food. }\end{array}$ & Yes & $68(68 \%)$ & $68(68 \%)$ & 67 (70.5\%) & $93(97.9 \%)$ \\
\hline
\end{tabular}


Table 3 (Continued).

\begin{tabular}{|c|c|c|c|c|c|c|}
\hline \multirow[t]{2}{*}{ \# } & \multirow[t]{2}{*}{ Items } & \multirow[t]{2}{*}{ Correct Response } & \multicolumn{2}{|c|}{$\begin{array}{l}\text { Control Group } \\
(n=100)\end{array}$} & \multicolumn{2}{|c|}{$\begin{array}{l}\text { Intervention Group } \\
(n=95)\end{array}$} \\
\hline & & & $\begin{array}{l}\text { Pre } \\
\text { N (\%) }\end{array}$ & $\begin{array}{l}\text { Post } \\
\text { N (\%) }\end{array}$ & $\begin{array}{l}\text { Pre } \\
\text { N (\%) }\end{array}$ & $\begin{array}{l}\text { Post } \\
\text { N (\%) }\end{array}$ \\
\hline 15 & $\begin{array}{l}\text { Egg, milk and milk products, meat and products, fish } \\
\text { and poultry, beans, lentils, soybeans, and chickpeas are } \\
\text { good examples of protein-source food. }\end{array}$ & Yes & 92 (92\%) & 92 (92\%) & $86(90.5 \%)$ & 94 (98.9\%) \\
\hline 16 & $\begin{array}{l}\text { Meat, fish, poultry, dried beans, peas, lentils, and some } \\
\text { fruits and vegetables are some examples of iron-source } \\
\text { food. }\end{array}$ & Yes & $84(84 \%)$ & $84(84 \%)$ & 78 (82.1\%) & 94 (98.9\%) \\
\hline 17 & $\begin{array}{l}\text { Carrot, cabbage, mango, red pepper, liver, fish, egg } \\
\text { yolks, and dairy products are good examples of vitamin } \\
\text { A-source food. }\end{array}$ & Yes & 73 (73\%) & 73 (73\%) & 72 (75.8\%) & $89(93.7 \%)$ \\
\hline 18 & $\begin{array}{l}\text { Seafood such as fish and food fortified by iodine are } \\
\text { good examples of iodine-source food. }\end{array}$ & Yes & 81 (8I\%) & 81 (8I\%) & $82(86.3 \%)$ & 95 (100\%) \\
\hline
\end{tabular}

$($ mean $=14.38, \mathrm{SD}=2.08)$ to the posttest $($ mean $=14.36$, $\mathrm{SD}=2.11),(t(99)=0.70, p=0.482)($ Table 4$)$.

\section{Dietary Practices Among the Two Groups Before and After the Intervention} Before health education, the majority of participants in the control and intervention groups reported that they were not smoking during the current pregnancy (97\% vs 97.9\%) which is considered a healthy practice. On the other hand, $56.8 \%$ of participants in the intervention group reported that they were eating protein-rich food daily, $63.2 \%$ were eating fruits daily, and only $32.6 \%$ were not skipping a meal before health education. These proportions have increased to $93.7 \%$, $77.9 \%$, and $71.6 \%$, respectively, after health education. Furthermore, $78.9 \%$ of participants in the intervention group reported that they were taking iron supplements and $71.6 \%$ decreased caffeine consumption before health education. These proportions have increased to $95.8 \%$ and $88.4 \%$, respectively, after health education. The proportions of participants in the control group who reported healthy practices were similar to those in the intervention group before health education. However, the proportions of healthy practices did not change among the control group after the health education, as this group did not receive any health education (Table 5).

Before health education, the result revealed no significant difference between the total dietary practices score of the intervention group (mean $=6.69, \mathrm{SD}=1.97)$ compared to the control group score $($ mean $=7.02, \mathrm{SD}=1.66),(t(193)=-1.24$, $p=0.21)$. After health education, the intervention group recorded significantly higher total dietary practices score (mean $=8.70, \mathrm{SD}=1.16)$ compared to the control group score $($ mean $=7.02, \mathrm{SD}=1.66),(t(193)=8.15, p<0.001)$. Furthermore, the result revealed a significant increase in the total dietary practices score of the intervention group from the pretest (mean $=6.69, \mathrm{SD}=1.97)$ to the posttest (mean=8.70, $\mathrm{SD}=1.16),(t(94)=-11.62, p<0.001)$. However, the correlation and $t$ of the total score of dietary practices were not

Table 4 Independent-Samples $t$-Test Between the Intervention Group and the Control Group Before and After the Health Education $(n=195)$

\begin{tabular}{|l|l|l|l|l|l|l|}
\hline & Intervention Group Mean (SD) & Control Group Mean (SD) & t & df & P & Mean Difference \\
\hline Before: & & & & & & \\
Total dietary Knowledge & $14.60(2.53)$ & $14.38(2.08)$ & 0.66 & 193 & 0.50 & 0.22 \\
Total dietary practice & $6.69(1.97)$ & $7.02(1.66)$ & -1.24 & 193 & 0.21 & -.32 \\
\hline After: & & & & & & \\
Total dietary Knowledge & $19.30(0.88)$ & $14.36(2.11)$ & 21.12 & 193 & 0.000 & 4.94 \\
Total dietary practice & $8.70(1.16)$ & $7.02(1.66)$ & 8.15 & 193 & 0.000 & 1.68 \\
\hline
\end{tabular}


Table 5 Dietary Practices of Pregnant Women $(n=195)$

\begin{tabular}{|c|c|c|c|c|c|c|}
\hline \multirow[t]{2}{*}{ \# } & \multirow[t]{2}{*}{ Items } & \multirow{2}{*}{$\begin{array}{l}\text { Correct } \\
\text { Response }\end{array}$} & \multicolumn{2}{|c|}{ Control Group } & \multicolumn{2}{|c|}{ Intervention Group } \\
\hline & & & $\begin{array}{l}\text { Pre } \\
\text { N (\%) }\end{array}$ & $\begin{array}{l}\text { Post } \\
\text { N (\%) }\end{array}$ & $\begin{array}{l}\text { Pre } \\
\text { N (\%) }\end{array}$ & $\begin{array}{l}\text { Post } \\
\text { N (\%) }\end{array}$ \\
\hline 1 & Do you skip any meal during the current pregnancy? & No & 47 (47\%) & 47 (47\%) & $31(32.6 \%)$ & $68(71.6 \%)$ \\
\hline 2 & Do you take additional meals during the current pregnancy? & Yes & $45(45 \%)$ & $45(45 \%)$ & $48(50.5 \%)$ & $57(60 \%)$ \\
\hline 3 & Do you take iron supplements during the current pregnancy? & Yes & $84(84 \%)$ & $84(84 \%)$ & 75 (78.9\%) & $91(95.8 \%)$ \\
\hline 4 & $\begin{array}{l}\text { Do you eat carbohydrate-rich food such as (bread, rice, pasta, or } \\
\text { potatoes) daily during the current pregnancy? }\end{array}$ & Yes & $64(64 \%)$ & $64(64 \%)$ & $58(61.1 \%)$ & 95 (100\%) \\
\hline 5 & $\begin{array}{l}\text { Do you eat protein-rich food such as (chicken, meat, yogurt, milk, or } \\
\text { eggs) daily during the current pregnancy? }\end{array}$ & Yes & $60(60 \%)$ & $60(60 \%)$ & $54(56.8 \%)$ & $89(93.7 \%)$ \\
\hline 6 & Do you eat fresh vegetables daily during the current pregnancy? & Yes & $83(83 \%)$ & $83(83 \%)$ & $73(76.8 \%)$ & $91(95.8 \%)$ \\
\hline 7 & Do you eat fruits daily during the current pregnancy? & Yes & $66(66 \%)$ & $66(66 \%)$ & $60(63.2 \%)$ & $74(77.9 \%)$ \\
\hline 8 & Do you follow your weight during pregnancy? & Yes & $82(82 \%)$ & $82(82 \%)$ & $76(80 \%)$ & $86(90.5 \%)$ \\
\hline 9 & $\begin{array}{l}\text { Do you reduce caffeine intake (tea or coffee) during the current } \\
\text { pregnancy? }\end{array}$ & Yes & $74(74 \%)$ & $74(74 \%)$ & $68(71.6 \%)$ & $84(88.4 \%)$ \\
\hline 10 & Do you smoke during the current pregnancy? & No & 97 (97\%) & 97 (97\%) & $93(97.9 \%)$ & $92(96.8 \%)$ \\
\hline
\end{tabular}

computed for the control group because the standard error of the difference was zero and no significant difference was found before and after the intervention (Table 4).

\section{Discussion}

This study aimed to examine the effect of health education on the levels of dietary knowledge and practices among pregnant women in Jordan. Before health education, the overall score of dietary knowledge among pregnant women was good in the control and intervention groups. Yet, there were some variations in the sub-scores of each item, which highlighted the need for further dietary counseling. The results revealed that the majority of participants answered correctly that food during pregnancy is important for the growth and development of the fetus, supplying heat and energy to bodies, and countering infection or disease. These results are congruent with those reported by an Ethiopian study in which more than $90 \%$ of pregnant women reported similar correct answers. ${ }^{8}$ The majority of participants in our study also identified the components of a balanced diet and reported the causes of undernutrition. In contrast, a study in Ethiopia found that, only half of the pregnant women reported adequate knowledge about a balanced $\operatorname{diet}^{22}$ and a study in Lebanon indicated that $65 \%$ of women did not know the causes of undernutrition. ${ }^{9}$ The findings of the current study may demonstrate some previous exposure to certain dietary-related topics among pregnant women, either at home or in the antenatal care setting. However, the total score of dietary practices was lower than the total score of knowledge in both groups before the health education indicating that adequate knowledge does not necessarily translate into a healthy practice. The only healthy practice that was already reported by over $95 \%$ of participants in both groups before health education was not smoking. This proportion is similar to those reported in Lebanon and Australia. ${ }^{9,23}$ Women in our study may have been aware of the impact of smoking on pregnancy outcomes. This might be also because the Jordanian culture discourages women from smoking, especially during pregnancy.

We hypothesized that providing health education effectively may improve dietary knowledge and practices among pregnant women. This hypothesis was supported by the findings of the current study as scores of dietary knowledge and practices improved significantly for the intervention group after receiving health education 
compared to the control group. Hence, it can be argued that health education was effective in enhancing dietary knowledge and practices among participants in this study. The results of this study are supported by the findings of previous experimental and quasi-experimental studies in Ethiopia, ${ }^{5}$ Iran, ${ }^{12}$ Brazil, ${ }^{24}$ and Australia. ${ }^{13}$ These studies revealed a significant increase in dietary knowledge and practices after providing health education.

Specific examples of knowledge improvements in the current study revealed that before health education, over $70 \%$ of participants in the intervention group recognized that anemia poses a health risk when a pregnant woman's diet lacks iron, identified the types of food and drinks that enhance or inhibit iron absorption, correctly recognized the examples of food sources, and identified the correct range of weight gain during pregnancy. However, these proportions have increased to over $90 \%$ after health education. In concordance, the before-after study that was conducted among pregnant women in Ethiopia revealed that the proportion of pregnant women with knowledge on eating a variety of food increased from $43.8 \%$ to $85.7 \%$. Similarly, knowledge on the duration of Iron supplementation and knowledge on the food source for iron increased from $35.5 \%$ to $92.1 \%$, and from $31.8 \%$ to $86.9 \%$, respectively. ${ }^{5}$

Specific examples of practice improvements in the current study showed also that, before health education, one third and two-thirds of participants in the intervention group reported that they were not skipping a meal and were eating fruits daily. These figures have increased to over $70 \%$ after health education. Furthermore, over $70 \%$ of the participants in the intervention group reported that they were taking iron supplements and eating vegetables daily before health education. These proportions have also increased to over $95 \%$ after health education. In congruence, the RCT that was conducted among pregnant women in Australia revealed that women who attended the workshop increased their consumption of fruit, vegetable, met fruit guidelines, and had a higher diet quality score $(p=0.027)$ compared with those who only received the usual care. ${ }^{13}$ Also, the study in Ethiopia revealed that a higher proportion of pregnant women changed their practice by eating 2 servings of green vegetables from $(46.1 \%$ to $88.2 \%)$ and adherence to Iron supplements (69\% to $100 \%)$. The results of the current and previous studies indicate the necessity of exposing pregnant women to consistent antenatal health education to encourage a greater commitment to better practices. ${ }^{5}$
The current study was limited by selecting pregnant women only from the central part of Jordan and by using a consecutive sample without random allocation of participants into groups. Furthermore, the study may have been exposed to self-report bias based on the type of questionnaire used. Thus, we recommend conducting interventional studies covering different geographical sites by using different sample characteristics, selecting random samples, and allocating random groups. It is also recommended to conduct studies examining perceptions of pregnant women toward the impact of health education in antenatal clinics. There are several challenges related to the nursing and midwifery practices in Jordan including traditional nursing practices that does not reflect holistic care, lack of nursing practice quality, and inadequate consideration given to primary health care services. ${ }^{16}$ Thus, incorporating social media applications to increase dietary knowledge and improve dietary practices in the perinatal period is important as this may improve maternal and fetal health in the Jordanian community. For policymakers, we suggest establishing regular and ongoing educational training programs for health care professionals, especially nurses and midwives. We also recommend adopting antenatal health education among Jordanian women.

\section{Conclusion}

It has been shown that including health education concerning dietary knowledge and practices in the care of pregnant women may improve their knowledge and practices. This may in turn have a positive effect on the health outcomes of pregnant women and their fetus as such. Hence, it is of importance for nurses and midwives to focus more on developing such practices to assess pregnant women's dietary status and apply health education strategies to enhance the dietary status of pregnant women.

\section{Funding}

This study was funded by the Deanship of Research in Jordan University of Science and Technology.

\section{Disclosure}

All authors report no conflicts of interest in this work.

\section{References}

1. Eshra DK, Ali I. Effect of nursing intervention on the beliefs and practices of pregnant women regarding vitamins and minerals intake. Int J Novel Res Healthc Nurs. 2016;3(1):66-80.

2. Soma-Pillay P, Catherine NP, Tolppanen H, Mebazaa A, Tolppanen H, Mebazaa A. Physiological changes in pregnancy. Cardiovas $J$ Afr. 2016;27(2):89-94. doi:10.5830/CVJA-2016-021 
3. World Health Organization. Assessment for nutrition-related disorders in women during pregnancy. 2019. Available from: https:/www.who.int elena/titles/assessment-methods-pregnancy/en/. Accessed April 19, 2020.

4. Alemayehu MS, Tesema EM. Dietary practice and associated factors among pregnant women in Gondar town northwest, Ethiopia, 2014. Int J Nutr Food Sci. 2015;4(6):707-712. doi:10.11648/j.ijnfs.20150406.27

5. Zelalem A, Endeshaw M, Ayenew M, Shiferaw S, Yirgu R. Effect of nutrition education on pregnancy-specific nutrition knowledge and healthy dietary practice among pregnant women in Addis Ababa. Clin Mother Child Health. 2017;14(3):265. doi:10.4172/20907214.1000265

6. Abujilban S, Hatamleh R, Al-Shuqerat S. The impact of a planned health educational program on the compliance and knowledge of Jordanian pregnant women with anemia. Women Health. 2019;59 (7):748-759. doi:10.1080/03630242.2018.1549644

7. Lim ZX, Wong JL, Lim PY, Soon LK. Knowledge of nutrition during pregnancy and associated factors among antenatal mothers. Int J Public Health Clin Sci. 2018;5(1):117-128.

8. Nana A, Zema T. Dietary practices and associated factors during pregnancy in northwestern Ethiopia. BMC Pregnancy Childbirth. 2018;18:183. doi:10.1186/s12884-018-1822-1

9. Harb D, Abou Haidar MY, Bou Yazbeck E. Knowledge, attitude and practices toward nutrition and diet during pregnancy among recently delivered women of Syrian refugees. J Refug Glob Health. 2018;1 (2):32-37. doi:10.18297/rgh/vol1/iss2/6

10. Fasola O, Abosede O, Fasola FA. Knowledge, attitude and practice of good nutrition among women of childbearing age in Somolu Local Government, Lagos State. J Public Health Afr. 2018;9(1):793. doi:10.4081/jphia.2018.793

11. World Health Organization. New guidelines on antenatal care for a positive pregnancy experience. 2016. https://www.who.int/reproductive health/news/antenatal-care/en/. Available from: Accessed April 20, 2019.

12. Fallah F, Pourabbas A, Delpisheh A, Veisani Y, Shadnoush M. Effects of nutrition education on levels of nutritional awareness of pregnant women in Western Iran. Int $J$ Clin Endocrinol Metab. 2013;11(3):175-178. doi:10.5812/ijem.9122

13. Wilkinson SA, McIntyre HD. Evaluation of the 'healthy start to pregnancy' early antenatal health promotion workshop: a randomized controlled trial. BMC Pregnancy Childbirth. 2012;12 (1):131. doi:10.1186/1471-2393-12-131

14. El-Qudah JM, Almajwal AM, Al-Momani MM, Alothman AM, AlUdatt $\mathrm{MH}$, Al-Qudah MM. Evaluation of food consumption in a sample of pregnant women from Jordan. Jordan J Agric Sci. 2015;11(1):20.
15. Tayyem RF, Allehdan SS, Alatrash RM, Asali FF, Bawadi HA. Adequacy of nutrients intake among Jordanian pregnant women in comparison to dietary reference intakes. Int J Environ Res Public Health. 2019;16(18):3440. doi:10.3390/ijerph16183440

16. Alyahya MS, Khader YS, Batieha A, Asad M. The quality of maternal-fetal and newborn care services in Jordan: a qualitative focus group study. BMC Health Serv Res. 2019;19(1):1-6. doi:10.1186/s12913-019-4232-9

17. Gupta KK, Attri JP, Singh A, Kaur H, Kaur G. Basic concepts for sample size calculation: critical step for any clinical trials! Saudi $J$ Anaesth. 2016;10(3):328. doi:10.4103/1658-354X.174918

18. Rolling TE, Hong MY. The effect of social cognitive theory-based interventions on dietary behavior within children. $J$ Nutrit Health Food Sci. 2016;4(5):1-9. doi:10.15226/jnhfs.2016.00179

19. World Health Organization. Healthy eating during pregnancy and breastfeeding. 2001. Available from: https:/www.euro.who.int/_data/ assets/pdf file/0020/120296/E73182.pdf. Accessed April 25, 2019.

20. World Health Organization. Nutrition of women in the preconception period, during pregnancy and the breastfeeding period. 2011. Available from: https://apps.who.int/gb/ebwha/pdf_files/EB130/ B130_11-ar.pdf.Accessed February 20, 2019.

21. American Pregnancy Association. Diet during pregnancy: healthy eating while pregnant. 2019. Available from: https://americanpregnancy.org/ pregnancy-health/diet-during-pregnancy/. Accessed August 12, 2019.

22. Zerfu TA, Biadgilign S. Pregnant mothers have limited knowledge and poor dietary diversity practices, but favorable attitude towards nutritional recommendations in rural Ethiopia: evidence from community-based study. BMC Nutr. 2018;4(1):1-9. doi:10.1186/ s40795-018-0251-x

23. Malek L, Umberger W, Makrides M, Zhou SJ. Adherence to the Australian dietary guidelines during pregnancy: evidence from a national study. Public Health Nutr. 2016;19(7):1155-1163. doi: $10.1017 / \mathrm{S} 1368980015002232$

24. Oliveira SC, Fernandes AF, Vasconcelos EM, et al. Effect of an educational intervention on pregnancy: a cluster-randomized clinical trial. Acta Paul Enferm. 2018;31(3):291-298. doi:10.1590/19820194201800041

\section{Publish your work in this journal}

The International Journal of Women's Health is an international, peerreviewed open-access journal publishing original research, reports, editorials, reviews and commentaries on all aspects of women's healthcare including gynecology, obstetrics, and breast cancer. The manuscript management system is completely online and includes a very quick and fair peer-review system, which is all easy to use. Visit http://www.dovepress.com/testimonials.php to read real quotes from published authors. 